\title{
SYSTEMATICS OF ISOTOPIC DISEQUILIBRA BETWEEN MINERALS OF LOW TEMPERATURE GARNET LHERZOLITES
}

\section{Günther and E. Jagoutz}

Max-Planck-Istitut für Chemie, Abteilung Kosmochemie, Saartrasse 23, 6500 Mainz, F.R.G.

The garnet bearing lherzolites of the southern African craton can be divided into two types:

1.) High temperature deformed garnet lherzolites $\left(1200-1400{ }^{\circ} \mathrm{C}\right)$

2.) Lower temperature $\left(900-1100^{\circ} \mathrm{C}\right.$ ) coarse (and deformed) garnet lherzolites (1).

The chemical equilibration of minerals under mantle PT conditions is an unsolved problem. For petrographic PT estimations to reconstruct geothermal gradient, it is essential to assume chemical equilibrium between the minerals. Since the multidimentional chemical reactions are not quantitatively understood yet, only isotopic analysis can provide informations on chemical equilibrium.between the minerals. Furthermore the isotopes are giving the only time information of the last chemical equilibration.

Spinell lherzolites from alkali basalts show a mineral Nd isotopic equilibrium between OPX and CPX (2) at the time of eruption High temperature deformed garnet lherzolites are in Nd isotopic equilibrium between CPX and garnet,.as they were sampled by the kimberlites, while the low temperature lherzolites are commonly not in isotopic equilibrium (3).

We investigated mineral separates of three coarse grain low temperature garnet harzburgites. Two of them contain some $\mathrm{CPX}(<5 \%)$. The samples were collected in Kimberley floors, S.A., in 1986, during a fieldtrip, by the courtesy of the Anglo American Company. The xenoliths were arranged according to their macroscopic appearance. Especially the texture of the garnets is striking. It is possible to classifie the xenoliths in order of "increasing deformation" of the garnets: In one endmember (EJ 8601) the garnet occurs only in several cm large clusters, intergrown with OPX little CPX and phlogopite. With "increasing deformation" the clusters become disordered and gradually smeared out, ending in a homogenous distribution of garnet. EJ 8604 shows garnet intergrown with OPX/CPX and little phlogopite, still as clusters, whereas EJ 8631 displays a much more homogenous distribution. of garnets. These clusters are suggesting to be the reaction products of a preexisting mineral phase.

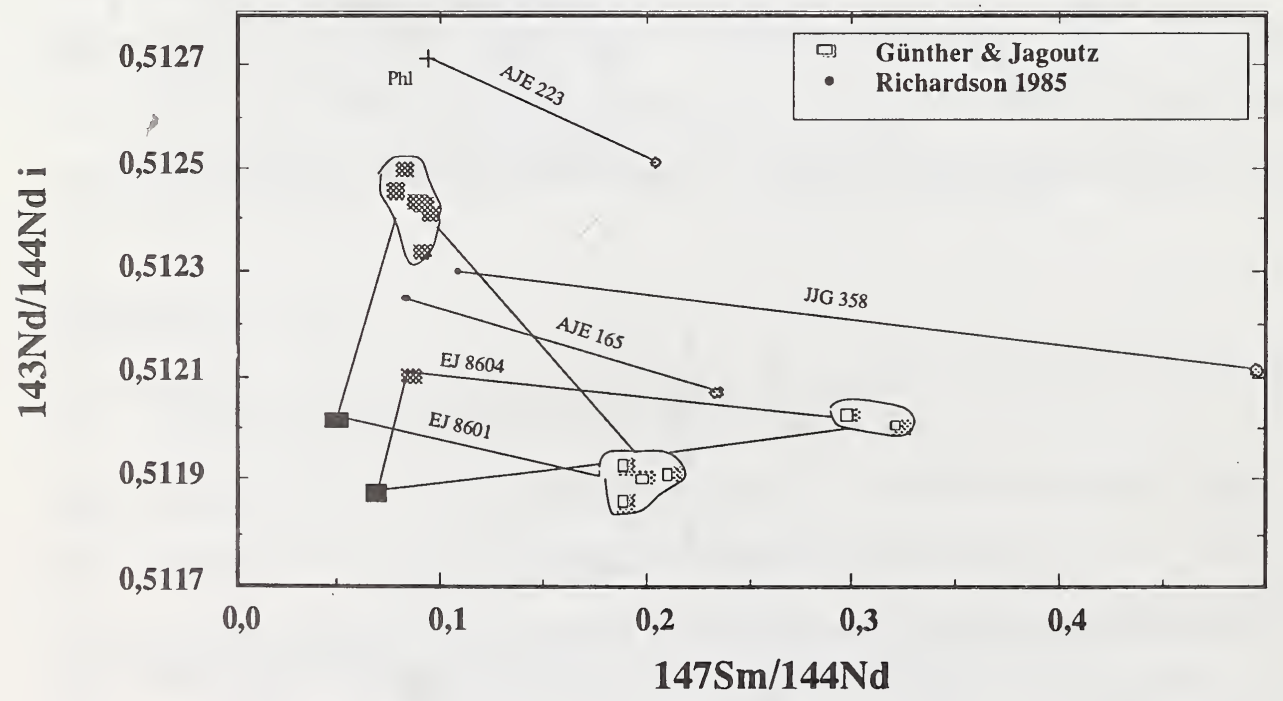

Fig. $1 \mathrm{Nd} / \mathrm{Sm}$ disequilibria (Symbols see Fig. 1) 
We analysed mineral separates for $\mathrm{Sr}, \mathrm{Nd}$, and $\mathrm{Pb}$ isotopic systematics. Although the $\mathrm{Sm} / \mathrm{Nd}$ ratios in garnets are about 5 to 10 times higher than in CPX and OPX, the Nd isotopic composition of garnet is less radiogenic, resulting in "future isochrones" with negative slopes. Similar results are reported by Richardson et al.(1985), as shown in Fig 1, while the sample EJ 8631, which contains the most deformed garnet cluster, is equilibrated in respect to the Nd isotpes, but their $\mathrm{Sr}$ isotopes are still recording a chemical

disequilibrium. It seems that the $\mathrm{Sr}$ isotopes are more resistant to equilibration. While the $\mathrm{Rb}$ content of all these minerals is to little to explain a variation in the Sr isotopic composition, the measured isotopic composition of the minerals varies over a wide range. Garnets are always containing very radiogenic Sr (Fig. 2). The lead composition of EJ 8601, which contains the least deformed garnet clusters shows an extreme composition in garnet (206/204: 32,09, 207/204: 16,41, 208/204: 42,18), while its CPX plots above the enriched part of the oceanic basalt field. The other CPX's are laying near the field of unradiogenic depleted mantle, the OPX lies near above the enriched part of the oceanic basaltic field (after 4), while the garnets have consitantly the most radiogenic lead values (Fig. 3). The ${ }^{208} \mathrm{~Pb}$ systematics shows, that the Th/U ratio in the garnets is lower than in OPX, also indicating an isotopic disequilibrium between these mineral phases (Fig. 3).

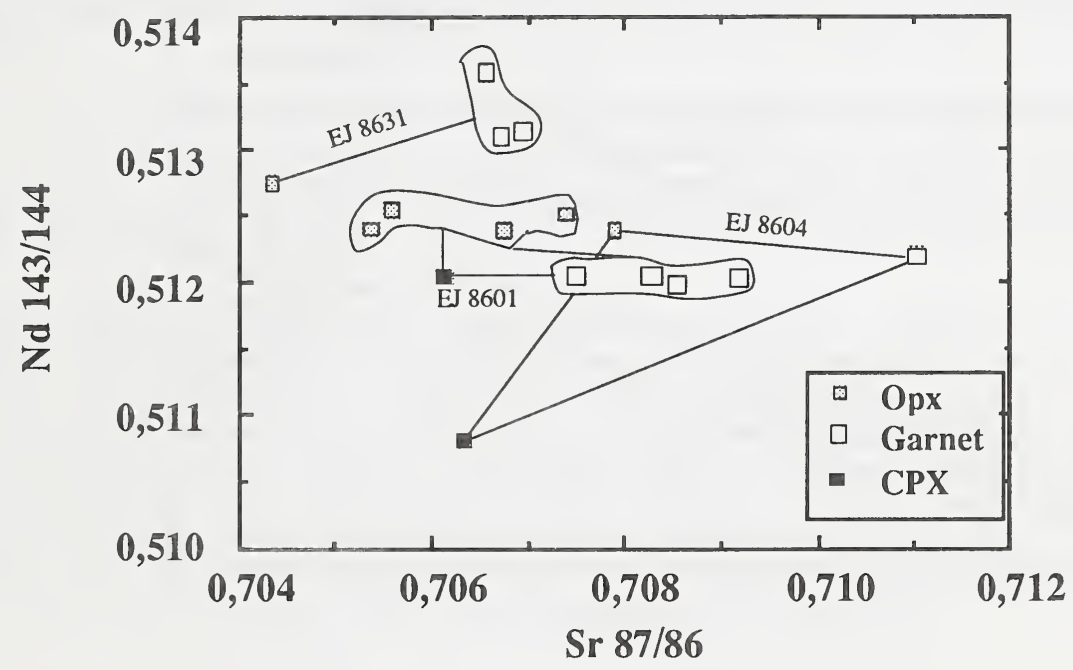

Fig. $2 \mathrm{Nd} / \mathrm{Sr}$ distribution plot

Since an information on the age can only be obtained in an equilibrated system, it is not possible to give an age estimate by using the above mentioned isotopic systematics. Only the $\mathrm{U} \mathrm{Pb}$ system opens the possibility to look through the different metamorphic episodes. While the 206/204 versus mu diagramm is giving the eruption age, the $\mathrm{Pb} / \mathrm{U}$ concordia diagram of EJ 8604 and EJ 8631 indicates a very old age of the protolith (more than 4 g.a.), and a young ( $200 \mathrm{ma}$ ) desturbance, which might be connected to the beginning of the eruption event. This young event might be the commmonly refered metasomatic episode (5). The very early differentiation of harzburgites was also suggessted by Boyd 1987 (6), according to their higher Si content.

The $\mathrm{Nd}$ and the $\mathrm{Sr}$ isotopic systematic proves that the minerals of garnet harzburgites, the comon low temperature or coarse granular xenolith from kimberlites, are not in chemical equilibrium We suggest that the garnet had a precursor mineral phase. Compared to CPX this mineral phase had a low $\mathrm{Sm} / \mathrm{Nd}$ and $\mathrm{Th} / \mathrm{U}$ ratio but a high $\mathrm{Rb} / \mathrm{Sr}$ and $\mathrm{U} / \mathrm{Pb}$ ratio. We propose that an aqueous fluid invaded a depleted harzburgite and a hydrous phase (possibly an amphibole) was crystallized. Also the $208 / 204$ versus 206/204 indicates an early disturbance of the protolith, which might also to be seen in the 207/204 versus 206/204, showing an "isochron" between OPX and garnet (EJ 8604) of about 1,4 g.a., which might be the age of hydratation. 
After a time of isotopic evolution this amphibole reacted to garnet+OPX + phlogopite+/-CPX, possibly caused by an episodic increasement of pressure, about 200 m.a.ago. During this event the primary CPX and OPX was not isotopically equilibrated (EJ 8601, EJ 8604), while the garnet inhereted the isotopic composition of the preexisting amphibole but lost some of its Nd U and Th. Since in the deformed sample (EJ 8631) the $\mathrm{Nd}$. was isotopically equilibrated at the time of sampling by the kimberlite $90 \mathrm{~m}$.a. ago the deformation might be only as old as the eruption.
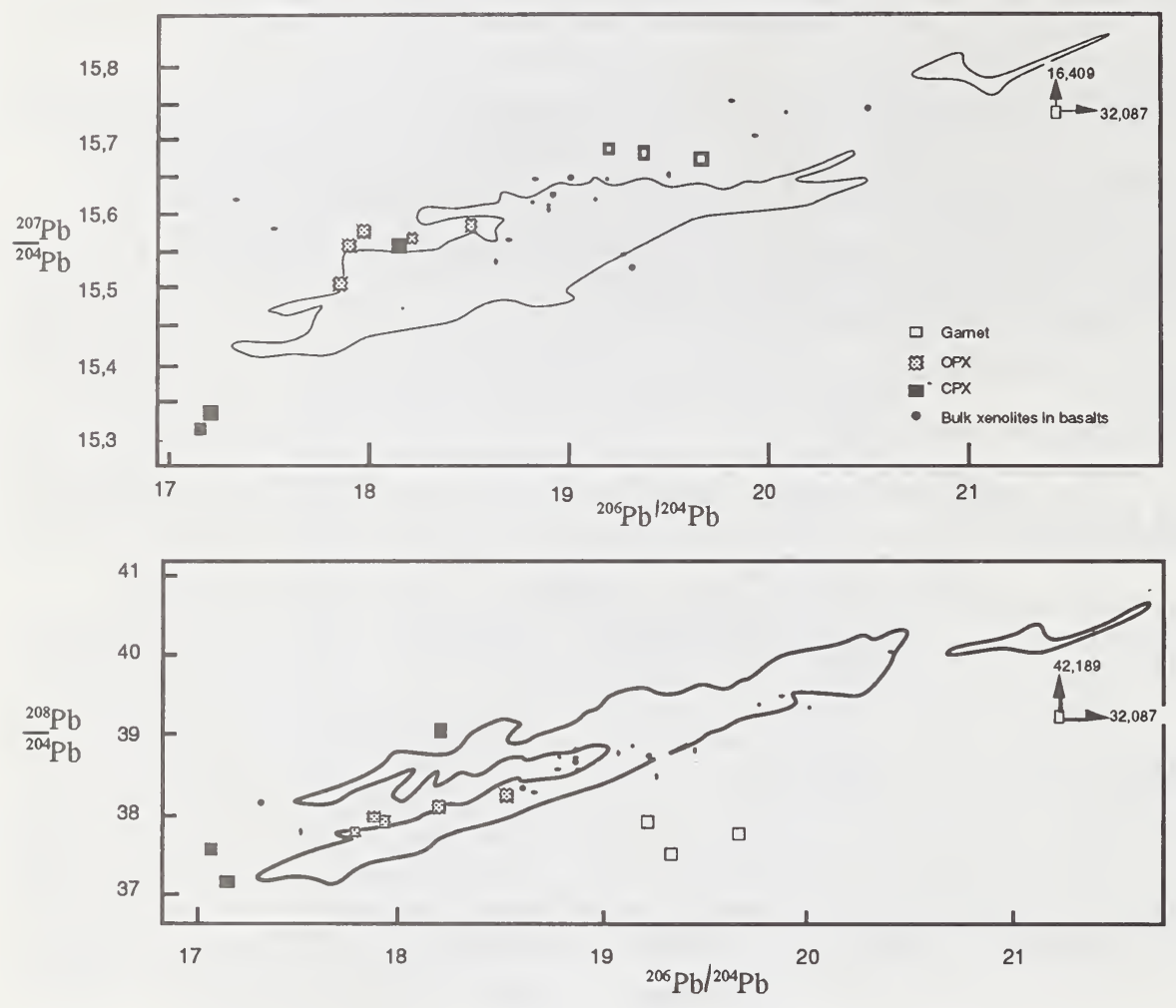

Fig. 3 Lead diagramm

\section{$\underline{\text { References }}$}

(1) Boyd, F.R.and Nixon, P.H. (1978) Ultramafic nodules from the Kimberley pipes, South Africa. Geochim. et Cosmochim Acta, 42, 1367-1382.

(2) Jagoutz, E.,Carlson, R.W. and Lugmair, G.W. (1980) Equilibrated Nd-unequilibrated Sr isotopes in mantle xenoliths. Nature, 286, 708-710.

(3) Richardson, S.H., Erlank, A.J.and Hart, S.R (1985) Kimberlite-borne garnet peridotite xenoliths from old enriched subcontinental lithosphere. Earth Plant. Sci. lett., 75, 116-128.

(4) Hart, S.R. (1988) Heterogenous mantle domains: signatures, genesis and mixing chronologies. Earth Planet. Sci. Lett., 90 , 273-296.

(5) Dawson, J.B.(1980) Kimberlites and their xenoliths, Springer, Berlin.

(6) Boyd, F.R. (1987) High- and low temperature garnet peridotite xenoliths and their possible relation to the lithosphere-asthenosphere boundary beneath southern Africa. In P.H. Nixon (ed.),.Mantle xenoliths, p. 403-412. Elsevier, Amsterdam. 